\title{
Determination of antiradical and antioxidant activity: basic principles and new insights *
}

\author{
Gunars Tirzitis ${ }^{1}$ and Grzegorz Bartosz 2,3 \\ 1 Laboratory of Membranoactive Compounds, Latvian Institute of Organic Synthesis, Riga, Latvia; 2 Department of Molecular Biophysics, University \\ of Łódź, ${ }^{3}$ Department of Biochemistry and Cell Biology, University of Rzeszów, Poland
}

\begin{abstract}
Although the term "antioxidant" is used very frequently, there are problems with the definition of antioxidants and estimation of antioxidant activity. The distinction between antioxidant and antiradical activities is not always obvious. This minireview discusses critically the principles, advantages and limitations of the most frequently used methods of estimation of antiradical and antioxidant activities.
\end{abstract}

Keywords: antioxidant, antiradical, DPPH, ABTS, hydroxyl radical

Received: 10 November, 2009; revised: 05 February, 2010; accepted: 06 February, 2010; available on-line: 11 May, 2010

\section{CURRENT STATE OF THE ART}

"It is difficult these days to open a popular science magazine or medical journal without seeing an article about the role of free radicals in human diseases" (Gutteridge \& Halliwell, 1994). This sentence written in 1994 by the leading scientists in the field of free radicals and antioxidants, John Gutteridge and Barry Halliwell is true today as well. Another statement of those authors, that "antioxidant is a term widely used but rarely defined" (Halliwell \& Gutteridge, 1999), has also remained true. A Google search for "antioxidants definition" brings more than 600000 entries! Halliwell and Gutteridge propose to define an antioxidant as "any substance that, when present at low concentration compared with those of an oxidizable substrate, significantly delays or prevents oxidation of that substrate" (Halliwell \& Gutteridge, 1999). This definition covers all oxidation processes, both radical and non-radical ones. But, as noted elsewhere, "a generic definition of an antioxidant is not experimentally constructive unless it is associated with the notion of the oxidant that has to be neutralized" (Azzi et al., 2004). Moreover, the validity of the term "antioxidant" depends on the environment of its action, viz. whether we consider an in vitro or in vivo action. In this context a precise definition of conditions and processes in which antioxidant action is studied becomes crucial. Outside this context, a statement that some compound is an antioxidant may not bring any biologically meaningful information.

The literature of the last decade concerning free radical reactions in vivo shows that our understanding of these processes in the organism, both under normal conditions and in pathological situations, has changed considerably. Free radicals and reactive oxygen species in general are no longer seen only as destructive factors but also (and perhaps first of all) as messengers involved in intracellular and intercellular signalling (Bartosz, 2005; 2009; Halliwell, 2006). The revision of the ideas on the role of free radical reactions in the functioning of cells and organisms has led to a new concept of redox equilibrium. According to this hypothesis, oxidative stress is a modulation of thiol redox reactions, involved mainly in signalling pathways. Therefore, non-radical oxidants (enzymatically generated hydrogen peroxide, other peroxides, quinones, etc.) play a basic role in the oxidation of thiols for the sake of signalling, without the necessity of formation of free radical intermediates (Ghezzi et al., 2005; Jones, 2006; 2008).

Similar changes are taking place with respect to our understanding of the role of vitamin $\mathrm{E}$ ( $\alpha$-tocopherol) in living processes. For a long time it was believed that the main function of vitamin $\mathrm{E}$ is its antioxidant action in biomembranes. Within the last few years it has become clear that the antioxidant activity of vitamin $\mathrm{E}$ is not the only one (and perhaps not the most important) of its physiological functions (Ricciarelli et al., 2001; Atkinson et al., 2008; Jones, 2008; Engin, 2009). The common belief of the beneficial health-improving action of plant phenolics has also been revised (Halliwell, 2007).

In view of the substantial changes in the understanding of the role of reactive oxygen species and antioxidants in living systems, a critical re-evaluation of the methods of determination of the antioxidant activity is also necessary.

\section{ANTIOXIDANT AND ANTIRADICAL ACTIVITY}

The general methods of determination of antioxidant activity are summarized in many reviews, including (Sanchez-Moreno, 2002; Huang et al., 2005; Frankel \& Finley, 2008). Due to their practical significance much attention is paid to studies of natural products and food supplements (Davalos et al., 2003; Moon \& Shinamoto, 2009). Numerous studies have demonstrated that the antioxidant activity measured depends substantially on the test system used (Janaszewska \& Bartosz, 2002; Bauzaite et al., 2003) and recommended to base any conclusions on at least two different test systems (Moon \& Shinamoto, 2009).

Most of the methods of determination of total antioxidant activity characterize the ability of the tested

e-mail: gunars.tirzitis@gmail.com

ॠhe paper was presented at the COST B-35 Work Group 4 Open Workshop "Natural and synthetic antioxidants", September 25-26, 2009, Rzeszów, Poland.

Abbreviations: ABTS, 2,2'-azino-bis(3-ethylbenzthiazoline-6-sulphonic acid; BHT, butylhydroxytoluene; DPPH, 1,1-diprenyl-2-picrylhydrazyl; TAS, total antioxidant status. 
compound or product to scavenge free radicals and/or to complex metal ions driving the oxidation process.

It should be emphasized that there is a great difference between "antiradical" and "antioxidant" activity and that they do not necessarily coincide. According to Burlakova and coworkers (1975) the antiradical activity characterizes the ability of compounds to react with free radicals (in a single free radical reaction), but antioxidant activity represents the ability to inhibit the process of oxidation (which usually, at least in the case of lipids, involves a set of different reactions). Consequently, all test systems using a stable free radical (for example, DPPH, ABTS, etc) give information on the radical scavenging or antiradical activity, although in many cases this activity does not correspond to the antioxidant activity. In order to obtain information about the real antioxidant activity with respect to lipids or food stabilization, it is necessary to carry out the study on the real product (plant oil, lipoproteins, etc.).

\section{DPPH AND GALVINOXYL ANTIRADICAL ACTIVITY TEST SYSTEMS}

1,1-Diphenyl-2-picrylhydrazyl (DPPH; I) is a stable free radical. On accepting hydrogen from a corresponding donor, its solutions lose the characteristic deep purple $\left(\lambda_{\max } 515-517 \mathrm{~nm}\right)$ colour. DPPH is very popular for the study of natural antioxidants (Villano et al., 2007). The PubMed database shows that this radical has been employed in more than 850 studies since 1969.

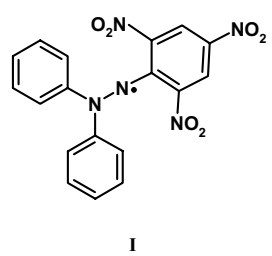

The antiradical activity of tested compounds is expressed as a relative or absolute decrease of concentration of DPPH or as $\mathrm{EC}_{50}$ (concentration of a compound decreasing the absorbance of a DPPH solution by $50 \%$ ). The rate of reaction of various antioxidants with DPPH differs (Janaszewska \& Bartosz, 2002). Very often the assay is performed according to the method described in (Bondet et al., 1997). In spite of the wide use of DPPH, this test system in some cases gives incorrect results and recommendations for the proper application of the method have been formulated (Nenadis \& Tsimidou, 2002; Molyneux, 2004; Sharma \& Bhat, 2009). It is necessary to note that in the DPPH test system BHT, a strong hydrophobic antioxidant, shows low reactivity (Nenadis \& Tsimidou, 2002; Musialik \& Litwinienko, 2005; Sharma \& Bhat, 2009). Some complications could be caused by partial ionization of the tested compounds, which affects the rate of their reaction with DPPH, making it pH-dependent (Musialik \& Litwinienko, 2005).

$\mathrm{DPPH}$ is a N-centred stable radical. From our experience the best way of measuring free radical scavenging (antiradical) activity would be to use the Ocentred stable radical galvinoxyl (II) which is more closely related to the physiologically acting oxygen radicals than is DPPH.

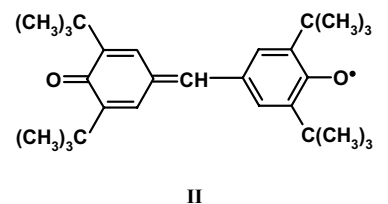

This stable radical is commercially available; its solutions have the absorbance maximum in the visible region $\left(\lambda_{\max }=432 \mathrm{~nm}\right)$ and it is recommended for studies with electron and hydrogen donating compounds (Shi et al., 2001). Comparing with DPPH, galvinoxyl is more reactive towards phenolics.

\section{ABTS-BASED TEST SYSTEMS}

The peroxidase substrate 2,2'-azino-bis(3-ethylbenzthiazoline-6-sulphonic acid) (ABTS), forming a relatively stable radical (ABTS*) upon one-electron oxidation, has become a popular substrate for estimation of total antioxidant capacity. Kinetic assays, including the commercialized TAS assay (Randox), are based on the inhibition of the formation of ABTS by one-electron oxidants (Bartosz \& Bartosz, 1999; Bartosz, 2003). A simpler and more frequently applied approach, is the decolorization of preformed ABTS (Re et al., 1999). An obvious drawback of ABTS-based assays is the promiscuity of reactions of ABTS' which is a nonphysiological free radical.

\section{HYDROXYL RADICAL SCAVENGING ACTIVITY}

Generation of hydroxyl radicals is crucial for the irreversible damage inflicted by oxidative stress (Halliwell \& Gutteridge, 1999). This generation mainly proceeds via Fenton reaction:

$\mathrm{H}_{2} \mathrm{O}_{2}+\mathrm{Fe}^{2+} \rightarrow \mathrm{Fe}^{3+}+\mathrm{HO}^{-}+\mathrm{HO}^{*}$

as well as in reaction between hypochlorous acid and superoxide anion:

$\mathrm{HOCl}+\mathrm{O}_{2}^{-} \rightarrow \mathrm{O}_{2}+\mathrm{Cl}^{-}+\mathrm{HO}^{*}$

The rate constant of the latter reaction is greater than that of the reaction of $\mathrm{Fe}^{2+}$ with $\mathrm{H}_{2} \mathrm{O}_{2}$ [2]. Decomposition of peroxynitrous acid also yields $\mathrm{HO}^{\circ}$ :

$\mathrm{HONOO} \rightarrow \mathrm{NO}_{2}+\mathrm{HO}^{\cdot}$

This reaction seems to be responsible for some 20$30 \%$ of the decay of peroxynitrite (Ferrer-Sueta \& Radi, 2009).

The hydroxyl radical is an extremely reactive species and reacts at a high rate $\left(k \sim 10^{9}-10^{10} \mathrm{M}^{-1} \cdot \mathrm{s}^{-1}\right)$ with all surrounding molecules - proteins, lipids, nucleic acids and sugars. Because the hydroxyl radical recombination

$\mathrm{HO}^{\bullet}+\cdot \cdot \mathrm{OH} \rightarrow \mathrm{H}_{2} \mathrm{O}_{2}$

is also very fast $\left(k=5 \times 10^{9} \mathrm{M}^{-1} \cdot \mathrm{s}^{-1}\right)$ the steady-state concentration of hydroxyl radical is practically zero (Halliwell \& Gutteridge, 1999). Consequently, in spite of their popularity, the methods for determination of reactivity between 


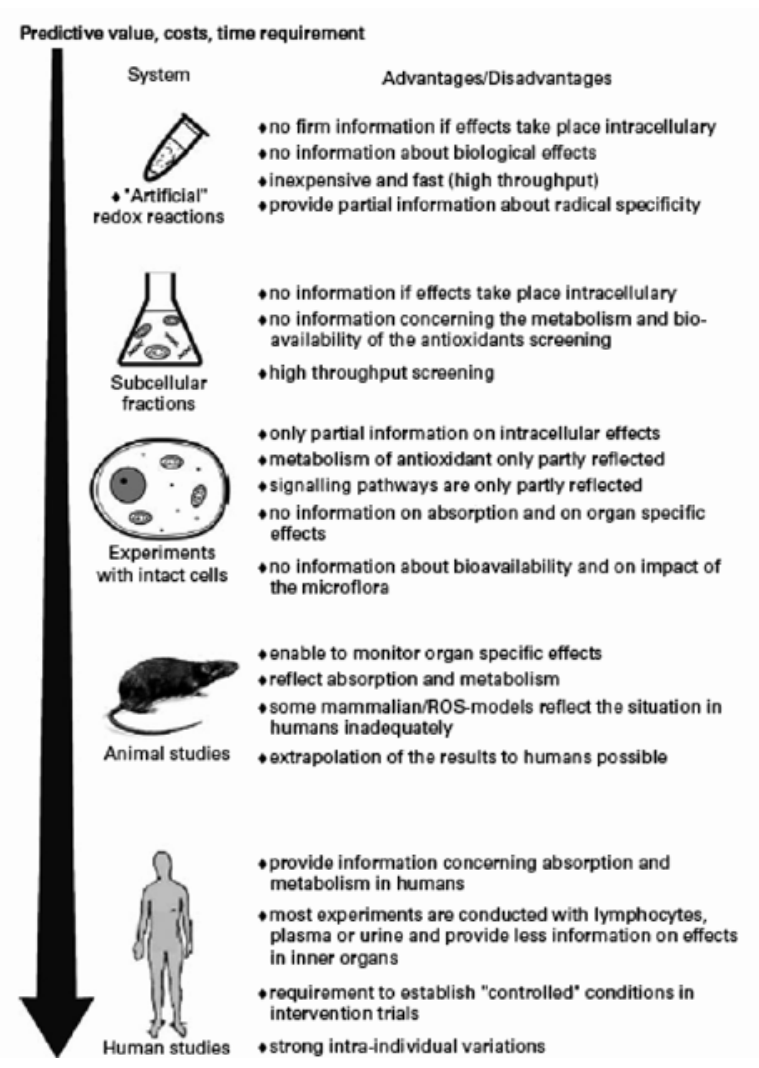

Figure 1. Advantages and disadvantages of different experimental approaches used to investigate ROS-protective effects of phytochemicals.

From (Knasmüllel et al., 2008), with authors' permission.

various compounds and hydroxyl radicals do not possess practical meaning.

\section{INTERPRETATION OF ANTIRADICAL AND ANTIOXIDANT STUDIES}

The determination of antioxidant activity for stabilization of lipids and lipid containing products poses no complications. DPPH or other simple test system for screening of a set of compounds or products (for example, plant extracts) can be used and an active compound (extract) chosen for a final test on the real product.

Analysis of clinical samples (usually blood plasma) requires more caution. The results obtained in simple as well as complicated antiradical and antioxidative activity test systems usually correlate poorly with the data on the physiological activity of the compounds. A hot current question is whether or not the radical-scavenging (or antioxidant) activity is responsible for the action of many drugs as well as for the activity of health improving products, or is it only a side effect of these compounds of no relevance to their biological effects? In many cases the latter possibility appears to be true, as demonstrated by large epidemiologic studies (for example, Huang et al., 2006; Bardia et al., 2008). Moreover, the question about the usefulness of the intake of elevated amounts of dietary polyphenols has been a subject of active debate (Halliwell, 2007), leading to a conclusion that antioxidant supplementation does not reduce gastrointestinal cancer (Bjelakovic et al., 2004), and a warning that excessive vitamin $\mathrm{E}$ supplements may even be harmful (Miller et al., 2005).

Therefore, it is suggested that the so-called "antioxidant hypothesis" should be considered an intellectual "shortcut" possibly biasing the real understanding of the molecular mechanisms underlying the beneficial effects of various classes of substances including food additives. On the basis of recent work, it is proposed that specific molecules of nutritional interest (in particular polyphenols) may act by their direct interaction with nuclear receptors and by modulation of the signalling pathways of the cell (Virgili \& Marino, 2008).

Recently, Knasmüller and co-authors (2008) carefully examined the methods of estimation of antioxidant/antiradical activities at various levels of biological organization and presented conclusions as the "pros and cons" of each method as well as for the suitability of specific methods for the evaluation of dietary antioxidants. The most important facets of this comparison are shown in Fig. 1.

\section{Acknowledgement}

This work was carried out in frame of the COST B35 action.

The authors express many thanks to Professor A. Kuksis (University of Toronto, Canada) for recommendations and elaboration of English.

\section{REFERENCES}

Atkinson J, Epand RF, Epand RM (2008) Tocopherols and tocotrienols in membranes: a critical review. Free Radic Biol Med 44: 739764.

Azzi A, Davies KJA, Kelly F (2004) Free radical biology — terminology and critical thinking. FEBS Lett 558: 3-6.

Bardia A, Tleyjieh JM, Cerhan JR, Sood AK, Limburg PJ, Erwin PJ, Montori VM (2008) Efficiacy of antioxidant supplementation in reducing pimary cancer incidence and mortality: systematic and metaanalysis. Mayo Clin Proc 83: 23-34.

Bartosz G (2003) Total antioxidant capacity. Adv Clin Chem 37: 219292.

Bartosz G (2005) The other face of oxygen. Free radicals in nature. Polish Scientific Publishers, Warsaw (in Polish).

Bartosz G (2009) Reactive oxygen species: Destroyers or messengers? Biochem Pharmacol 77: 1303-1315.

Bartosz G, Bartosz M (1999) Antioxidant activity: what do we measure? Acta Biochim Pol 46: 23-29.

Bauzaite R, Venscutonis PR, Gruzdiene D, Tirzite D, Tirzitis G (200) Radical scavenging and antioxidant activity of various plants grown in Lithuania. In Food Technology and Quality Evaluation. Dris R, Sharma A, eds. pp 183-193. Science Publishers, In3, United States.

Bjelakovic G, Nikolova D, Simonetti RG, Glood C (2004) Antioxidant supplements for prevention of gastrointestinal cancer: a systematic review and meta-analysis. Lancet 364: 1219-1228.

Bondet V, Brand-Williams W, Berset C (1997) Kinetics and mechanism of antioxidant activity using the DPPH free radical method. Lebensmitt Wissensch Technol 30: 609-615.

Burlakova EB, Alesenko AV, Molochkina EM, Palmina NP, Khrapova NG (1975) Bioantioxidants in radiation damages and malignant growth. Moscow: Nauka (in Russian).

Davalos A, Gomez-Cordoves C, Bartolome B (2003) Commercial dietary antioxidant supplements assayed for their antioxidant activity by different methodologies. J Agric Food Chem 51: 2512-2519.

Engin KN (2009) Alpha-tocopherol: looking beyond an antioxidant. Mol Vision 15: 855-860.

Ferrer-Sueta G, Radi R (2009) Chemical biology of peroxynitrite: kinetics, diffusion, and radicals. ACS Chem Biol 20: 161-177.

Frankel EN, Finley JW (2008) How to standardize the multiplicity of methods to evaluate natural antioxidants. I Agric Food Chem 56: 4901-4908.

Ghezzi P, Bonetto V, Fratelli M (2005) Thiol-disulfide balance: from the concept of oxidative stress to that of redox regulation. Antiox Redox Signal 7: 964-972.

Gutteridge JMC, Halliwell B (1994) Antioxidants in nutrition, bealth, and disease. Oxford University Press, Oxford, New York, Tokyo. 
Halliwell B (2006) Reactive species and antioxidants. Redox biology is a fundamental theme for aerobic life. Plant Physiol 141: 312-322.

Halliwell B (2007) Dietary polyphenols: Good, bad, or indifferent for our health? Cardiovasc Res 73: 341-347.

Halliwell B, Gutteridge JMC (1999) Free radicals in biology and medicine: Oxford University Press.

Huang D, Ou B, Prior RL (2005) The chemistry behind antioxidant capacity assays. J Agric Food Res 53: 1841-1856.

Huang HY, Caballero B, Chang S, Alberg A, Semba R, Schneyer C, Wilson RF, Chang TY, Prokopowicz G, Barnes GJ 2nd, Vassy J, Bass EB (2006) Multivitamin/mineral supplements and prevention of chronic disease. Evid Rep Technol Assess 139: 1-117.

Janaszewska A, Bartosz G (2002) Assay of total antioxidant capacity: comparison of four methods as applied to human blood plasma. Scand J Clin Lab Invest 62: 231-236.

Jones DP (2006) Redefining oxidative stress. Antiox Redox Signal 8: 1865-1879.

Jones DP (2008) Radical-free biology of oxidative stress. Am J Physiol Cell Physiol 295: C849-C868.

Knasmüller S, Nersesyan A, Nišik M, Gerner C, Mikulits W, Erlich V, Hoelzl C, Szakmary A, Wagner K-H (2008) Use of conventional and -omics based methods for health claims of dietary antioxidants: a critical overview. Brit J Nutr 99 E (Suppl 1): ES3-ES52.

Miller ERI, Pastor-Barriuso R, Dalal D, Riemersma RA, Appel IJ, Guallar E (2005) High-dosage vitamin E supplementation may increase all-cause mortality. Ann Internal Med 142: 37-46.

Molyneux P (2004) The use of the stable free radical diphenylpicrylhydrazyl (DPPH) for estimating antioxidant activity. Songklanakrin J Sci Technol 26: 211-216.
Moon J-K, Shinamoto T (2009) Antioxidant assays for plant and food components. J Agric Food Chem 57: 1655-1666.

Musialik M, Litwinienko G (2005) Scavenging of DPPH radicals by vitamin $\mathrm{E}$ is accelerated by its partial ionization: the role of sequential proton loss electron transfer. Org Lett 7: 4951-4954.

Nenadis N, Tsimidou M (2002) Observation on the estimation of scavenging activity of phenolic compounds using rapid 1,1-diphenyl-2picrylhydrazyl (DPPH) tests. J Am Oil Chem Soc 79: 1191-1195.

Re R, Pellegrini N, Proteggente A, Pannala A, Yang M, Rice-Evans C (1999) Antioxidant activity applying an improved ABTS radical cation decolorization assay. Free Radic Biol Med 26: 1231-1237.

Ricciarelli R, Zingg J-M, Azzi A (2001) Vitamin E: protective role of a Janus molecule. FASEB J 15: 2314-2325.

Sanchez-Moreno C (2002) Review: Methods used to evaluate the free radical scavenging activity in foods and biological systems. Food Sci Technol Int 8: 121-137.

Sharma OP, Bhat TK (2009) DPPH antioxidant assay revisited. Food Chem 113: 1201-1205.

Shi H, Noguchi N, Niki E (2001) Galvinoxyl method for standardizing electron and proton donating activity. Methods Enzymol 335: 157-166.

Villano D, Fernandez-Pachon MS, Moya ML, Troncoso AM, GarciaParilla MC (2007) Radical scavenging ability of phenolic compounds towards DPPH free radical. Talanta 71: 230-235.

Virgili F, Marino M (2008) Regulation of cellular signals from nutritional molecules: a specific role for phytochemicals beyond antioxidant activity. Free Radic Biol Med 45: 1205-1216. 